\title{
Effects of TET1 knockdown on gene expression and DNA methylation in porcine induced pluripotent stem cells
}

\author{
Anran Fan, Kuiying Ma, Xinglan An, Yu Ding ${ }^{1}$, Peipei An, Guangqi Song, Lina Tang, Sheng Zhang, \\ Peng Zhang, Wentao Tan, Bo Tang, Xueming Zhang and Ziyi Li \\ Jilin Provincial Key Laboratory of Animal Embryo Engineering, The Center for Animal Embryo Engineering of \\ Jilin Province, College of Veterinary Medicine and ${ }^{1}$ College of Animal Science, Jilin University, 5333 Xi An Da Lu, \\ Changchun, Jilin 130062, China \\ Correspondence should be addressed to Z Li; Email: ziyi@jlu.edu.cn; X Zhang; Email: zhxueming@yahoo.com
}

\begin{abstract}
TET1 is implicated in maintaining the pluripotency of embryonic stem cells. However, its precise effects on induced pluripotent stem cells (iPSCs), and particularly on porcine iPSCs (piPSCs), are not well defined. To investigate the role of TET1 in the pluripotency and differentiation of piPSCs, piPSCs were induced from porcine embryonic fibroblasts by overexpression of POU5F1 (OCT4), SOX2, KLF4, and MYC (C-MYC). siRNAs targeting to TET1 were used to transiently knockdown the expression of TET1 in piPSCs. Morphological abnormalities and loss of the undifferentiated state of piPSCs were observed in the piPSCs after the downregulation of TET1. The effects of TET1 knockdown on the expression of key stem cell factors and differentiation markers were analyzed to gain insights into the molecular mechanisms underlying the phenomenon. The results revealed that knockdown of TET1 resulted in the downregulated expression of pluripotency-related genes, such as $L E F T Y 2, K L F 2$, and $S O X 2$, and the upregulated expression of differentiation-related genes including PITX2, HAND1, GATA6, and LEF1. However, POU5F1, MYC, KLF4, and NANOG were actually not downregulated. Further analysis showed that the methylation levels of the promoters for POU5F1 and MYC increased significantly after TET1 downregulation, whereas there were no obvious changes in the promoters of SOX2, KLF4, and NANOG. The methylation of the whole genome increased, while hydroxymethylation slightly declined. Taken together, these results suggest that TET1 may play important roles in the self-renewal of piPSCs and the maintenance of their characteristics by regulating the expression of genes and the DNA methylation.

Reproduction (2013) $\mathbf{1 4 6} 569-579$
\end{abstract}

\section{Introduction}

DNA methylation is one of the most important epigenetic markers; it has been well characterized and demonstrated to be involved in many biological processes, including transposable element silencing, genomic imprinting, and X chromosome inactivation (Bird 2002, Surani et al. 2007, Sasaki \& Matsui 2008, Cedar \& Bergman 2009). However, the mechanism underlying DNA demethylation is largely unknown and remains controversial (Ooi \& Bestor 2008). Recently, the functions of the Teneleven translocation (TET) family of methyldioxygenases (TET1, TET2, and TET3) have been implicated in DNA demethylation via converting the 5-methylcytosine $(5 \mathrm{mC})$ of DNA to 5-hydroxymethylcytosine (5hmC) (Tahiliani et al. 2009). Tet1 is expressed in embryonic stem cells (ESCs) and preimplantation embryos; it is also involved in the self-renewal and the maintenance of pluripotency of the ESCs and the specification of the inner cell mass (Ito et al. 2010). Tet1-depleted ESCs mediated by RNAi exhibited skewed differentiation toward the trophectoderm fate, significant reduction in the content of $5 \mathrm{hmC}$, and the loss of their ESC identity (Freudenberg et al. 2012).

Induced pluripotent stem cells (iPSCs) exhibit many similarities to ESCs. Since their first generation (Takahashi \& Yamanaka 2006), there has been an explosive development of iPSCs because they can be generated from an easily accessible cell source, completely overcoming the ethical drawbacks associated with the use of human ESCs, and they allow patientcustomized therapy that avoids immunological rejection (Park et al. 2008). Despite their undoubted promise in regenerative medicine, many obstacles must be overcome before using these cells as a source of transplant material; there is an especially strong need for animal models whose anatomy and physiology better resemble those of humans than do those of the mouse to test the efficacy and the safety of the iPSCs transplantation. Pigs are a potentially useful model in this regard because of the low probability of disease transfer between humans and pigs (Cheng \& Xiao 2009) and their similarities to 
humans in their long life span, organ size, immunology, and physiology (Ezashi et al. 2009). Recently, three papers that were published almost simultaneously by different groups described the generation of porcine iPSCs (piPSCs; Esteban et al. 2009, Ezashi et al. 2009, Wu et al. 2009). The piPSCs provide an attractive model to study certain human diseases or assess the therapeutic applications of iPSCs in a large animal model. The process of reprogramming somatic cells to become iPSCs has been shown to be accompanied by changes in DNA methylation and certain epigenetic changes. Thus, piPSCs provide a favorable system to study the epigenetic features that are prerequisite for pluripotency (Mattout et al. 2011). In this study, we derived piPSCs and investigated whether TET1 played an important role in the epigenetic regulation of these cells.

\section{Materials and methods}

\section{Reagents and animals}

Chemicals and media were purchased from Sigma unless otherwise stated. Cell culture-related reagents were purchased from Gibco unless otherwise stated. Specific pathogen-free mice and non-obese diabetic/severe combined immunodeficient (NOD/SCID) mice were purchased from Vital River Laboratories (Beijing, China) and pregnant pigs were purchased from the Jilin University Pig Farm. All the experiments involving animals were approved by and complied with the experimental practices and standards of the Animal Welfare and Research Ethics Committee at Jilin University (approval ID: 20101008-2).

\section{Induction of piPSCs from porcine embryonic fibroblasts}

The 293T cells were plated in T-75 flasks (Corning, New York, USA) containing DMEM/F $12+10 \%$ fetal bovine serum (FBS, HyClone, Utah, USA) until reaching $80 \%$ confluency. To package the retroviruses, pMXs retroviral vectors encoding mouse SOX2, KLF4, POU5F1 (OCT4), and MYC (C-MYC) (SKOM) or GFP CDNAs were individually used to cotransfect the cells with Vsvg and Gap using Lipofectamine 2000 (Invitrogen). The retroviruses were collected 48 and $72 \mathrm{~h}$ later. Porcine embryonic fibroblasts (PEFs) were isolated from the 30-day-old fetuses of purebred Yorkshire pigs and maintained in DMEM containing 10\% FBS, 2 mM L-glutamine, 50 units $/ \mathrm{ml}$ penicillin, and $50 \mathrm{mg} / \mathrm{ml}$ streptomycin. The cells were seeded at a density of $10^{6}$ per well in six-well plates and maintained in a $5 \% \mathrm{CO}_{2}$ atmosphere at $37.8^{\circ} \mathrm{C}$. After $24 \mathrm{~h}$, the cells were infected with cocktails of the previously packaged retroviruses. A pMXs retroviral vector encoding GFP, which also served as a negative control for iPS cell induction, was used to monitor the transfection efficiency. After 5 days of normal culture, the PEFs were trypsinized $(0.25 \%$ tripping, Gibco) for passage onto a feeder layer of mitomycin C mitotically inactivated mouse embryonic fibroblasts (MEFs) in ES medium containing 20\% Knockout Serum Replacement, $10 \mathrm{mM}$ 2-mercaptoethanol, $0.1 \mathrm{mM}$ non-essential amino acids, $2 \mathrm{mM}$ GlutaMAX, $1 \mathrm{mM}$ sodium pyruvate, $10 \mathrm{ng} / \mathrm{ml}$ stem cell factor (Peprotech, New Jersey, USA), $10 \mathrm{ng} / \mathrm{ml}$ human basic fibroblast growth factor (bFGF, Peprotech), and $1000 \mathrm{U}$ ESGRO (Millipore, Billerica, USA). When ESC-like colonies appeared, they were harvested and maintained by manual passage to expand the cultures every $4-5$ days. The colonies that had a normal ES-like morphology were used for alkaline phosphatase (AP) staining. Embryoid bodies (EBs) expressing specific markers of the three germ layers (endoderm, AFP; mesoderm, BMP4; and ectoderm, GFAP) were also detected. The specific primers for the pluripotency genes are listed in Table 1.

\section{SiRNA transfection into piPSCs}

The piPSCs were cultured on gelatin-coated plates in the ES medium described earlier. siRNAs targeted to TET1 (siRNA \#1,

Table 1 Primers and PCR conditions.

\begin{tabular}{|c|c|c|c|}
\hline Primer & $\begin{array}{l}\text { Primer pair } \\
\text { sequences } \\
\left(5^{\prime}-3^{\prime}\right)\end{array}$ & $\begin{array}{c}\begin{array}{c}\text { Annealing } \\
\text { temperature } \\
\left({ }^{\circ} \mathrm{C}\right) \times \text { cycle } \\
\text { no. }\end{array} \\
\end{array}$ & $\begin{array}{c}\text { Product } \\
\text { sizes }\end{array}$ \\
\hline \multicolumn{4}{|l|}{ RT-PCR } \\
\hline$M Y C$ & $\begin{array}{l}\text { F-ggattccgcctcgtt } \\
\text { R-tctccaagcatcactcg }\end{array}$ & $55 \times 40$ & 185 \\
\hline GAPDH & $\begin{array}{l}\text { F-acctgccgcctggagaaacc } \\
\text { R-gaccatgaggtccaccaccctg }\end{array}$ & $60 \times 40$ & 252 \\
\hline GATA6 & $\begin{array}{l}\text { F-ctggtgtctgccaaagcg } \\
\text { R-aagggatgcgaggcgtaa }\end{array}$ & $57 \times 40$ & 243 \\
\hline HAND1 & $\begin{array}{l}\text { F-ggcgagaagaggattaaaggg } \\
\text { R-caatcaaggatgggcagtatg }\end{array}$ & $59 \times 40$ & 201 \\
\hline KLF2 & $\begin{array}{l}\text { F-ggcaccgacgacgacctcaaca } \\
\text { R-ccgtagcaactccgacaccaage }\end{array}$ & $60 \times 40$ & 186 \\
\hline KLF4 & $\begin{array}{l}\text { F-cggcaaaacctacacgaagagt } \\
\text { R-agttcatctgagcgggcaaat }\end{array}$ & $59 \times 40$ & 120 \\
\hline LEF1 & $\begin{array}{l}\text { F-attcaggcaaccctaccc } \\
\text { R-agctacgacgttcgctct }\end{array}$ & $60 \times 40$ & 186 \\
\hline LEFTY2 & $\begin{array}{l}\text { F-gggatgaaatgggctgagaactggg } \\
\text { R-tgctgacgatcacgggcaacgag }\end{array}$ & $57 \times 40$ & 169 \\
\hline NANOG & $\begin{array}{l}\text { F-cttattcaggacagccctgattcttc } \\
\text { R-aagacggcctccaaatcactg }\end{array}$ & $59 \times 40$ & 614 \\
\hline POU5F1 & $\begin{array}{l}\text { F-gtcgccagaagggcaaac } \\
\text { R-cagggtggtgaagtgaggg }\end{array}$ & $57 \times 40$ & 125 \\
\hline PITX2 & $\begin{array}{l}\text { F-cttacggaagcccgagtc } \\
\text { R-cgcccagttgttgtatgagt }\end{array}$ & $57 \times 40$ & 171 \\
\hline SOX2 & $\begin{array}{l}\text { F-ccctgcagtacaactccatgac } \\
\text { R-ggtgccctgctgcgagta }\end{array}$ & $59 \times 40$ & 86 \\
\hline TET1 & $\begin{array}{l}\text { F-ggcaccctgaagcggatgagc } \\
\text { R-gagcaccgagccgtgaatgg }\end{array}$ & $60 \times 40$ & 143 \\
\hline \multicolumn{4}{|c|}{ Semiquantitative PCR } \\
\hline$A F P$ & $\begin{array}{l}\text { F-tattggagaaatgttcgcagtc } \\
\text { R-ccagggtttatgggcatc }\end{array}$ & $56 \times 24$ & 349 \\
\hline$B M P 4$ & $\begin{array}{l}\text { F-gcgtagccccaagcatcacc } \\
\text { R-atccctctactaccatctcctg }\end{array}$ & $60 \times 24$ & 341 \\
\hline GFAP & $\begin{array}{l}\text { F-ctcgecgctcctatgtct } \\
\text { R-gccttgttctgctgctc }\end{array}$ & $59 \times 24$ & 291 \\
\hline GAPDH & $\begin{array}{l}\text { F-acctgccgcctggagaaacc } \\
\text { R-gaccatgaggtccaccaccctg }\end{array}$ & $60 \times 24$ & 252 \\
\hline LIN28 & $\begin{array}{l}\text { F-cagagtaagctgcacatggagg } \\
\text { R-gtaggctggctttccetgtg }\end{array}$ & $60 \times 24$ & 559 \\
\hline NANOG & $\begin{array}{l}\text { F-cttattcaggacagccctgattcttc } \\
\text { R-aagacggcctccaaatcactg }\end{array}$ & $58 \times 24$ & 614 \\
\hline POU5F1 & $\begin{array}{l}\text { F-caaactgaggtgcctgcccttc } \\
\text { R-attgaacttcaccttccctccaacc }\end{array}$ & $57 \times 24$ & 125 \\
\hline SOX2 & $\begin{array}{l}\text { F-ggttacctcttcttcccactcca } \\
\text { R-caaaaatagtccсcсcaaaagaag }\end{array}$ & $59 \times 24$ & 439 \\
\hline
\end{tabular}


Table 2 Primers and amplicon information of bisulfite sequence PCR.

\begin{tabular}{|c|c|c|c|c|c|}
\hline Genes & GenBank ID & Location & Primer sequence & CpG sites & Length \\
\hline$K L F 4$ & NW_003609455 & 439364-439701 & $\begin{array}{l}\text { F-ttgattataaattaaggggaggg } \\
\text { R-caaccaaaaatctcaaaacattt }\end{array}$ & 17 & 336 \\
\hline$N A N O G^{\mathrm{a}}$ & GU433187.1 & $16-515$ & $\begin{array}{l}\text { F-ggagatttaaaggagttttaggttaagaaa } \\
\text { R-tctcctccaaatattaaaaatatcaaaaa }\end{array}$ & 10 & 500 \\
\hline POU5F1 & NW_003610613 & $53168-53453$ & $\begin{array}{l}\text { F-tggttgagttttaagggtttt } \\
\text { R-ccaacttctccttatccaactt }\end{array}$ & 24 & 286 \\
\hline SOX2 & NW_ 003611770 & 123967-124348 & $\begin{array}{l}\text { F-ggggggatataaaggttttta } \\
\text { R-aaactcaaacttctctccctttc }\end{array}$ & 23 & 382 \\
\hline$M Y C$ & NW_003609985 & 895195-895492 & $\begin{array}{l}\text { F-tttgtttgataggttggaaaga } \\
\text { R-aaaacccattttacaaaacacc }\end{array}$ & 16 & 298 \\
\hline
\end{tabular}

a Zhao MT, Rivera RM \& Prather RS 2013 Locus-specific DNA methylation reprogramming during early porcine embryogenesis. Biology of Reproduction $\mathbf{8 8} 48$.

siRNA \#2, siRNA \#3, and siRNA \#4), non-sense siRNA (negative control), and FAM-fluorescein-labeled non-sense siRNA (FAM-siRNA) oligonucleotides were chemically synthesized by GenePharma Co., Ltd. (Shanghai, China). The oligonucleotide sequences are listed in Table 2. The transfection efficiencies of different ratios of siRNA to Lipofectamine 2000 were determined using FAM-siRNA. The transfection of specific siRNAs was performed under the optimized conditions (Table 3). The dissociated piPSCs were seeded on gelatincoated 24-well plates in ES medium (400 $\mu \mathrm{l} /$ well). The cells in each well were transfected with 30 pmol siRNAs in ES medium for each well. Briefly, Lipofectamine $(2 \mu \mathrm{l})$ and siRNAs (30 pmol) were premixed with Opti-MEM (50 $\mu$ l, Invitrogen) respectively. Then they were mixed and incubated at room temperature for 15-30 min before applying to the cells. The transfected cells of each well were split into three wells of 24-well plate the next day and cultured in ES medium for $24 \mathrm{~h}$. The total RNAs were extracted from the cells $48 \mathrm{~h}$ after transfection with siRNA. To analyze TET1 downregulation, the dissociated piPSCs were plated in one well of a 24-well plate; $24 \mathrm{~h}$ after transfection, the cells were replated in another 24-well plate for $24 \mathrm{~h}$, after which they were used for RT-PCR.

\section{Semiquantitative PCR and real-time PCR analysis}

The total RNAs from the piPSCs were extracted using RNAiso Plus (TaKaRa, Shiga, Japan). A RevertAid First-Strand cDNA Synthesis Kit (Fermentas, Vilnius, Lithuania) was used to synthesize the first-strand cDNAs, according to the manufacturer's instructions, immediately after RNA isolation. Semiquantitative PCRs were performed in a $50 \mu \mathrm{l}$ volume containing $2 \mu \mathrm{l}$ cDNA, $25 \mu \mathrm{l}$ rTaq premix (TaKaRa), $22 \mu \mathrm{l}$ RNase-free water, and $0.5 \mu \mathrm{l}$ each of the forward and reverse primers $(10 \mathrm{pmol})$ for each gene. To determine optimal cycles of amplification, PCR products were obtained from 18, 20, 22, 24 , and 26 cycles respectively. All the products were conducted on ethidium bromide-stained agarose gels. When the cycles exceeded 24 cycles, the intensity of PCR bands did not change any more. Real-time PCRs were performed in a $25 \mu \mathrm{l}$ volume containing $2 \mu \mathrm{l}$ cDNA, $12.5 \mu \mathrm{l}$ SYBR Green Master Mix (TaKaRa), $9.5 \mu \mathrm{l}$ RNase-free water, and $0.5 \mu \mathrm{l}$ each of the forward and reverse primers $(10 \mathrm{pmol})$ for each gene. A reaction mix was formulated for the sample and for the nonreverse transcriptase control reactions. The program used for the amplification of each gene consisted of a denaturing cycle of $3 \mathrm{~min}$ at $95^{\circ} \mathrm{C}$ and 40 cycles of PCR $\left(95^{\circ} \mathrm{C}\right.$ for $20 \mathrm{~s}, 55^{\circ} \mathrm{C}$ for $45 \mathrm{~s}$, and $95^{\circ} \mathrm{C}$ for $1 \mathrm{~min}$ ) and cooling at $4{ }^{\circ} \mathrm{C}$. Relative gene expression was determined using real-time PCR and the $2^{-\Delta \Delta C T}$ method (Livak \& Schmittgen 2001). Triplicate PCR amplifications were performed for each sample and the values were normalized to the internal control of porcine GAPDH.

\section{Immunocytochemical staining of piPSCs}

The piPSCs colonies were plated in 24-well plates that were previously seeded with a feeders layer for 1 day. After washing with cold PBS and fixation in 4\% paraformaldehyde for $15 \mathrm{~min}$, the cells were rinsed with cold PBS $3 \times 5$ min, permeabilized with $0.1 \%$ Triton X-100 in cold PBS for $15 \mathrm{~min}$, and blocked with blocking solution (PBS containing 5\% BSA $+0.1 \%$ Triton $\mathrm{X}-100$ ) for $1 \mathrm{~h}$ before incubation with primary antibodies overnight in a humidified chamber at $4{ }^{\circ} \mathrm{C}$. The primary antibodies used in this study included antibodies against OCT4 (1:100, Abcam, Cambridge, UK ab18976), SOX2 (1:100, Sigma, AV38232), NANOG (1:100, Abcam, ab80892), REX1 (1:100, Abcam, ab50828), SSEA4 (1:100, Abcam, ab16287), and TET1 (1:100, Santa Cruz, sc-163443). After three washes in PBS, the cells were incubated with secondary antibodies (Alexa Fluor 568 goat anti-mouse, 1:400, Invitrogen; Alexa Fluor 488 goat anti-rabbit, 1:400, Invitrogen) for $2 \mathrm{~h}$. Finally, the cells were incubated with Hoechst 33342 for $15 \mathrm{~min}$ and again washed three times with PBS. Images were acquired using an Axiovert 200 (Nikon) and the AxioVision Software.

Table 3 Sequences of siRNA oligonucleotides.

\begin{tabular}{ll}
\hline Name & Sequences of siRNA $\left(5^{\prime}-3^{\prime}\right)$ \\
\hline $\begin{array}{c}\text { Non-sense } \\
\text { siRNA }\end{array}$ & Sense: UUC UCC GAA CGU GUC ACG UTT \\
Non-sense & Sense: UUC ACG UGA CAC GUU CGG AGA ATT \\
FAM-siRNA & Anti-sense: ACG UGA CGU GUC ACG UTT \\
siRNA \#1 & Sense: GAA GCA GUG UAC ACA UAA UGA ATT \\
& Anti-sense: AUU AUG UGU ACA CUG CUU CTT \\
siRNA \#2 & Sense: GGC CAG AAC AGA ACA UUC ATT \\
& Anti-sense: UGA AUG UUC UGU UCU GGC CTT \\
siRNA \#3 & Sense: GCA GCU AGC UAU AGA GUA UTT \\
& Anti-sense: AUA CUC UAU AGC UAG CUG CTT \\
siRNA \#4 & Sense: GCA GAU GGC CGU GAC ACA AAUTT \\
& Anti-sense: AUU UGU GUC ACG GCC AUC UGC TT \\
\hline
\end{tabular}

Reproduction (2013) 146 569-579 


\section{AP staining of piPSCs}

AP staining was performed as we described previously (Tang et al. 2012). Briefly, the piPSCs were cultured at a low density for 5 days. On the fifth day, the medium was discarded and the piPSCs were fixed with $4 \%$ paraformaldehyde in PBS for 1-2 min and then washed with rinse buffer. A sufficient volume of staining solution was added to cover each well and the cells were incubated in the dark at room temperature for $15 \mathrm{~min}$. The wells were rinsed with rinse buffer and the cells were covered with PBS to prevent drying. The colonies expressing AP were counted.

\section{Teratoma formation and analysis}

To test the pluripotency of piPSCs in vivo, pig iPS cells were treated using collagenase IV, harvested, and s.c. injected into dorsal flanks and armpits of NOD/SCID mice $\left(\sim 5 \times 10^{6}\right.$ cells per site). After 4 weeks, solid tumors were observed. The tumors were collected, sectioned, and processed for hematoxylineosin staining and were histologically analyzed.

\section{Methylation analysis: bisulfite-treated sequencing and touchdown PCR (BSP)}

For bisulfite sequencing, both pre-transfected cells and 48-h post-transfected cells were collected by centrifugation at $100 \mathrm{~g}$ for $10 \mathrm{~min}$ after washing with cold PBS. Genomic DNA was extracted using a TIANamp Genomic DNA Kit (Tiangen, Beiing, China) and subjected to bisulfite conversion using an EZ DNA Methylation Direct Kit (Zymo Research, Los Angeles, USA) according to the manufacturer's instructions. The bisulfitemodified DNA was subjected to PCR. To increase the specificity and sensitivity of the reactions, touchdown PCR was performed using hot-start polymerase. The cycling program involved two separate phases. Phase 1 was the touchdown phase, which started with an annealing temperature at $\mathrm{Tm}+10^{\circ} \mathrm{C}$ of the primers and then decreased the annealing temperature by $1{ }^{\circ} \mathrm{C}$ per cycle until $\mathrm{Tm}-5{ }^{\circ} \mathrm{C}$ of the primers was reached, for a total of 15 cycles. Phase 2 was a generic amplification stage of 15 cycles using the final annealing temperature determined in Phase 1. Finally, the PCR products were cloned into pMD18-T Vector (TaKaRa) and sequenced.

\section{Dot-blot assay}

Genomic DNA was isolated both from pre-transfected and 48-h post-transfected cells, and the concentrations were measured. Identical amounts of DNA were denatured at $95{ }^{\circ} \mathrm{C}$ for $15 \mathrm{~min}$ and rapidly transferred into an ice bath before being individually spotted on a nitrocellulose membrane. The blotted membrane was washed three times with $2 \times \mathrm{SSC}$ buffer and air-dried at $80{ }^{\circ} \mathrm{C}$ for $2 \mathrm{~h}$. The blots were blocked with $5 \%$ nonfat milk. After three washes with TBST for 10 min each time, they were incubated with $5 \mathrm{mC}$ primary antibody $(1: 1000$, Eurogentec, BI-MECY-1000, Liege, Belgium) or with $5 \mathrm{hmC}$ primary antibody (1:5000, Active Motif, Carlsbad, USA) respectively. After five washes with TBST for $10 \mathrm{~min}$ each time, the blots were incubated with anti-rabbit or anti-mouse horseradish peroxidase (HRP) conjugated secondary antibodies (1:4000, Bios, Shanghai, China). The dots were visualized using the SuperSignal Pico Chemiluminescent Substrate detection reagents (Thermo, Waltham, UK).

\section{Statistical analysis}

The data were analyzed by a one-way ANOVA, using Statistics Production and Service Solution Software (SPSS, version 16.0). Differences were considered significant at the value of $P<0.05$ and highly significant at the value of $P<0.01$.

\section{Results}

\section{Generation of piPSCs}

Retroviral vectors overexpressing the classic mouse SKOM cassette were packaged using 293T cells (Fig. 1A) and then employed to reprogram the PEFs. The reprogramming protocol was shown as the schematic diagram (Fig. 1B). The day when PEFs were infected was marked as D0. Colonies with a human ESC-like morphology appeared on approximately the tenth day after transduction. These partially reprogrammed colonies exhibited a dispersed and amorphic appearance (Fig. 1C). On day 14, the ESClike colonies were large, flattened, and round with clear boundaries (Fig. 1D). The colony-component cells were transferred to 24-well plates coated with feeder layer for expansion and further characterization. These colonies were AP positive (Fig. 1E). Semiquantitative RT-PCR indicated that they expressed endogenous POU5F1, SOX2, NANOG, and LIN28 (Fig. 1F). The piPSCs differentiated to form EBs on culture in the absence of bFGF and Lif on a nonadhesive substratum (Fig. 1G). When these EBs were subsequently cultured for a longer time on a gelatin-coated surface, they attached to the substratum, began to spread, and displayed overt signs of differentiation (Fig. 1H). The expression of all the markers of the three embryonic layers (endoderm, $A F P$; mesoderm, BMP4; and ectoderm, GFAP) was detected in the EBs (Fig. 1I). Solid tumors formed after 4 weeks when piPSCs were injected into NOD/SCID mice. Tumors contained tissues derived from three germ layers, including ectoderm-derived neural epithelium (Fig. 1J), mesodermderived striated muscle (Fig. 1K) and blood vessel (Fig. 1L), and endoderm-derived crypta-like structures (Fig. 1M). Immunocytochemical staining indicated that colony cells were OCT4, SOX2, NANOG, and SSEA4 positive (Fig. 2A, B, C and D).

\section{Knockdown of TET1 in piPSCs by siRNAs}

We confirmed that TET1 was indeed expressed in the piPSCs (Fig. 3A, B, C, D, E, F, G and H). A fluoresceinlabeled non-sense control siRNA was used to optimize the transfection conditions for the piPSCs (Fig. $3 \mathrm{I}$ and J). The optimal concentration of siRNA was determined to 


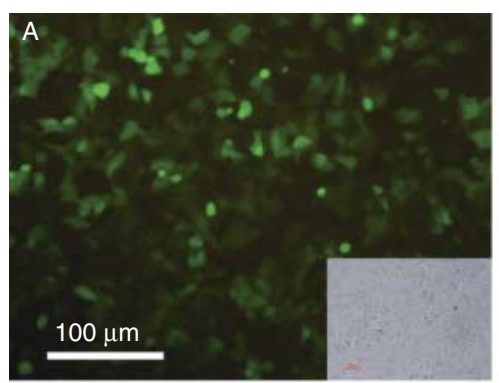

B
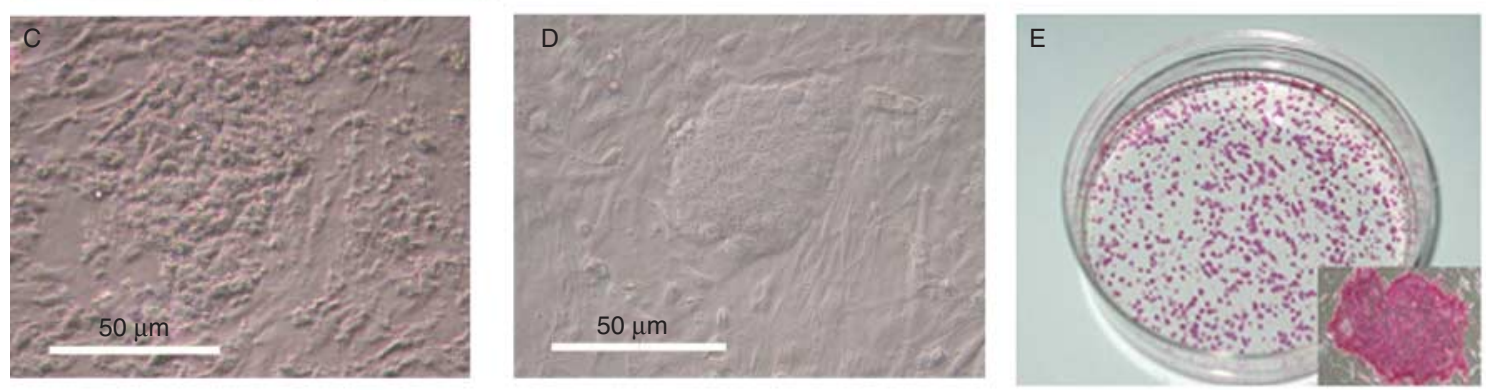

$\mathrm{F}$
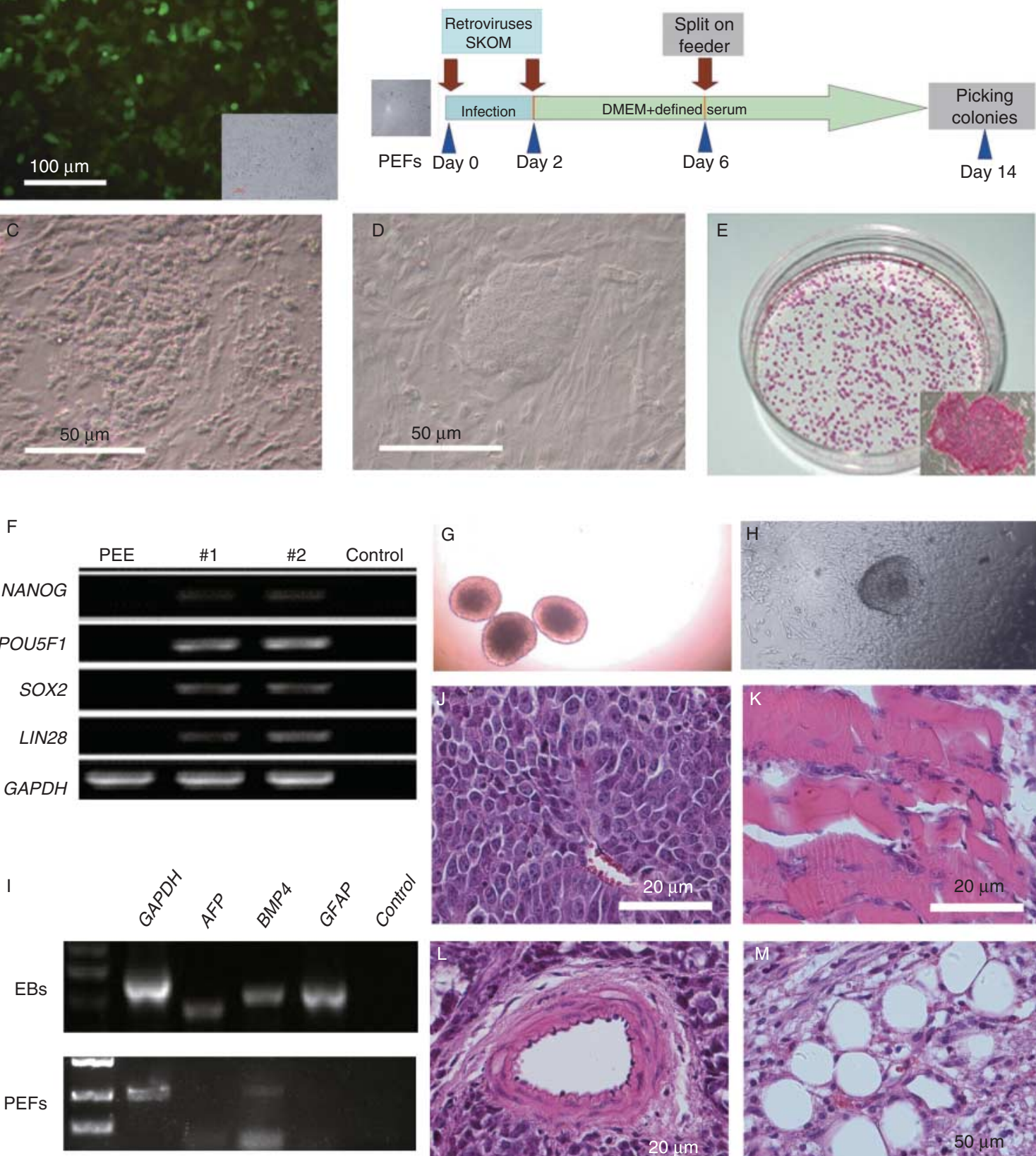

G
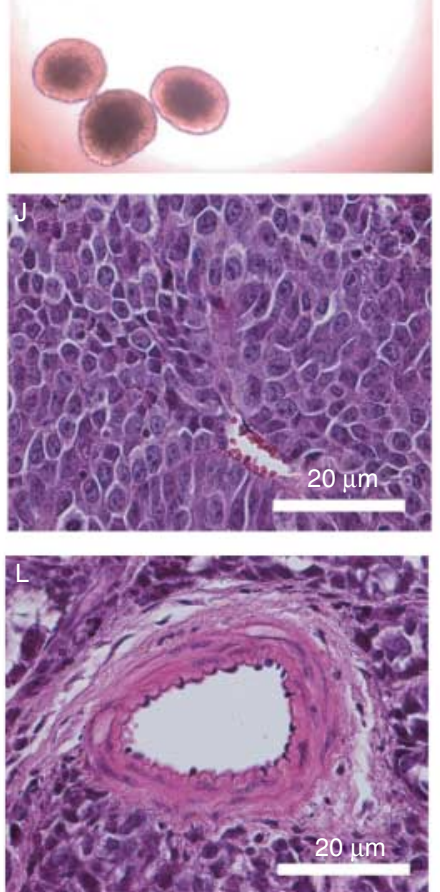
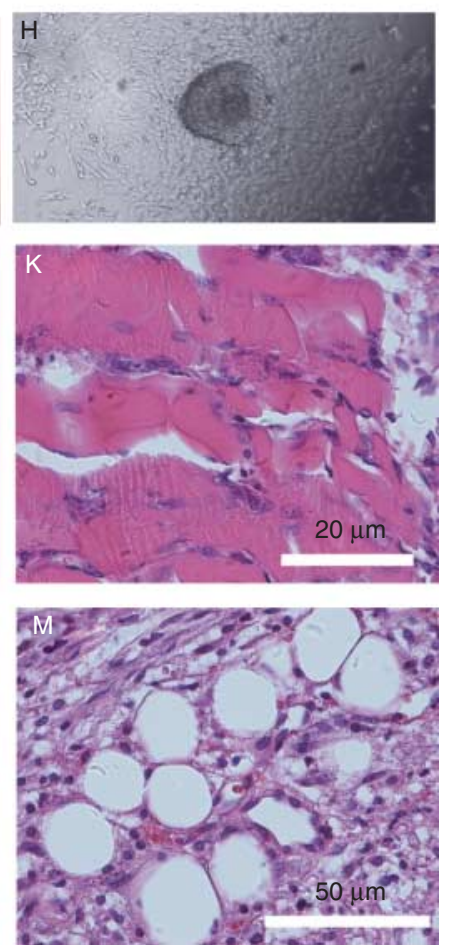

Figure 1 Generation and characterization of piPSCs. Packaging of the retroviral vectors encoding the cDNAs was evaluated using fluorescence microscopy $72 \mathrm{~h}$ after transfection. The expression of GFP indicated that successful packaging of the retroviruses had occurred (A). Schematic diagram of the reprogramming protocol illustrated the process from the infection to colony-picking. PEFs were derived from 30-day-old fetuses and infected twice, on days 0 and 2, with retroviruses. Six days after infection, PEFs were replated on a feeder layer. Starting on day 14 , classical (similar to those of human ESC) morphological changes (cells becoming rounded and aggregating) appeared, and the colonies were picked (B). The morphology of PEFs changed during the reprogramming process from the moment of infection to colony-picking (C and D). The day of the first retrovirus infection is D0. Starting on D9, partially reprogrammed colonies with human ESC-like morphology first became visible, but they were dispersed and amorphic (C). On day 14, the colonies were large, flattened, and round with clear boundaries and exhibited the classic ESC-like morphology (D). The piPSC colonies expressed AP (E). Semiquantitative PCR using two selected piPSC lines indicated the expression of the pluripotency genes NANOG, POU5F1, SOX2, and LIN28 (F). EBs formed when the colonies were cultured in vitro(G). When EBs were differentiated for a longer time, they attached to the substratum, began to spread, and displayed overt signs of differentiation $(\mathrm{H})$. The expression of three embryonic layers markers (endoderm, AFP; mesoderm, BMP4; and ectoderm, GFAP) were detected (K). GAPDH was used as a loading control, uninfected PEFs were used as a negative control, and $\mathrm{dd}_{2} \mathrm{O}$ was used as a mock control (I). Teratoma formed after piPSCs were injected into NOD/SCID mice, and tumors contained tissues derived from three germ layers, including ectoderm-derived neural epithelium (J), mesoderm-derived striated muscle (K) and blood vessel (L), and endoderm-derived cryptae-like structures $(\mathrm{M})$. 

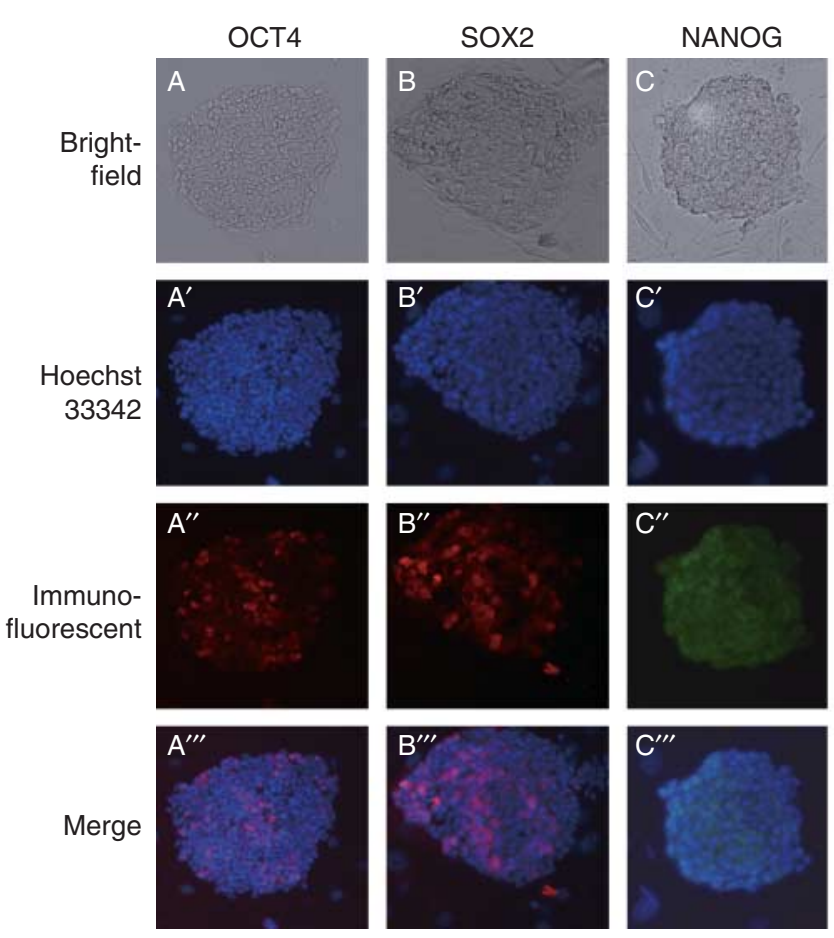

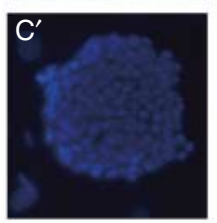

SSEA4
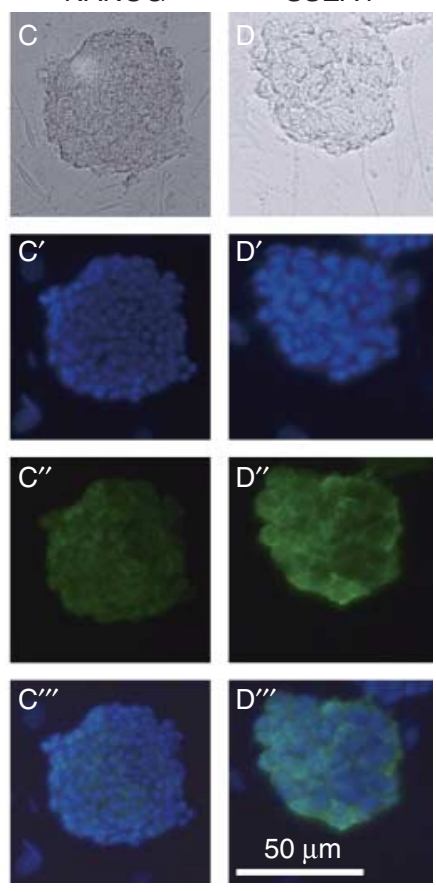

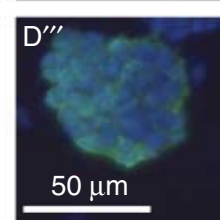

Figure 2 Immunofluorescence staining of pluripotent markers. Immunofluorescence staining of the pluripotent markers OCT4 (A, $\mathrm{A}^{\prime}, \mathrm{A}^{\prime \prime}$ and $\left.\mathrm{A}^{\prime \prime \prime}\right)$, SOX2 (B, $B^{\prime}, B^{\prime \prime}$ and $\left.B^{\prime \prime \prime}\right)$, NANOG $\left(C, C^{\prime}, C^{\prime \prime}\right.$ and $\left.C^{\prime \prime \prime}\right)$, and SSEA4 (D, $\mathrm{D}^{\prime}, \mathrm{D}^{\prime \prime}$ and $\left.\mathrm{D}^{\prime \prime \prime}\right)$ in piPSC colonies cultured on MEF feeder layers were shown. Nuclear counterstaining was proceeded with Hoechst 33342. be 30 pmol. The final condition used to transfect the iPSCs was to suspend them in normal, fully supplemented ES medium with 30 pmol siRNA mixed with $2 \mu \mathrm{l}$ transfection agent. To identify whether the each of the four TET1 siRNAs or the non-sense siRNA was transfected into the piPSCs, the expression of TET1 was examined $48 \mathrm{~h}$ after transfection. The results demonstrated that siRNA \#2 downregulated TET1 more effectively than did the other TET1 siRNAs (Fig. 3K).

\section{Changes in morphology and expression of stem cell markers and differentiation markers in piPSCs after knockdown of TET1}

Morphological examination of the piPSCs was conducted after TET1 siRNA transfection. Changes were found in the siRNA \#2 group, in which efficient downregulation of TET1 was also observed. These piPSCs were differentiated and lost the growth characteristics of colonies; they appeared dispersed and amorphic without clear boundaries between them and the surrounding feeder cells, while no similar outcomes were observed in other three TET1 siRNA groups and the mock group (Fig. 4A, B, C, D and E), in which the downregulation of TET1 was not as pronounced (Fig. 3K). To gain an insight into the molecular mechanism underlying this morphological phenomenon and identify whether TET1 downregulation had an effect on the expression of genes closely related to the piPSCs identity, the expression levels of several pluripotencyrelated genes and differentiation-related genes were analyzed at $48 \mathrm{~h}$ after transfection. The results showed that the knockdown of TET1 resulted in upregulated expression of differentiation-related genes including PITX2, HAND1, GATA6, and LEF1 (Fig. 4F) and downregulated expression of pluripotency-related genes such as LEFTY2, KLF2, and SOX2 (Fig. 4G). Interestingly, the stem cell genes POU5F1, MYC, KLF4, and NANOG were actually not downregulated in the TET1 knockdown piPSCs (Fig. 4G).

\section{Changes in the methylation and hydroxymethylation status in piPSCs after TET1 downregulation}

The methylation status of the promoters for the pluripotency-related genes (SKOM) was examined using BSP after TET1 siRNA transfection. The results demonstrated that the methylation levels in the promoters of POU5F1 and $\mathrm{MyC}$ were obviously increased (Fig. 5A, B, C, D, E and F), while there was no evident changes in the promoters of $S O X 2, K L F 4$, and NANOG (Fig. 5G, H, I, J, K, L, M, N and O). Evaluation of the $5 \mathrm{hmC}$ and $5 \mathrm{mC}$ levels in the whole genomes of the piPSCs after TET1 siRNA transfection was conducted using the dot-blot assay. The results revealed that after TET1 knockdown, the total $5 \mathrm{hmC}$ content decreased, while the total $5 \mathrm{mC}$ content increased (Fig. 5P and Q).

\section{Discussion}

Recently, piPSCs were successfully established by three independent groups almost simultaneously (Esteban et al. 2009, Ezashi et al. 2009, Wu et al. 2009). Danish Landrace pigs (Wu et al. 2009) and Tibetan miniature 

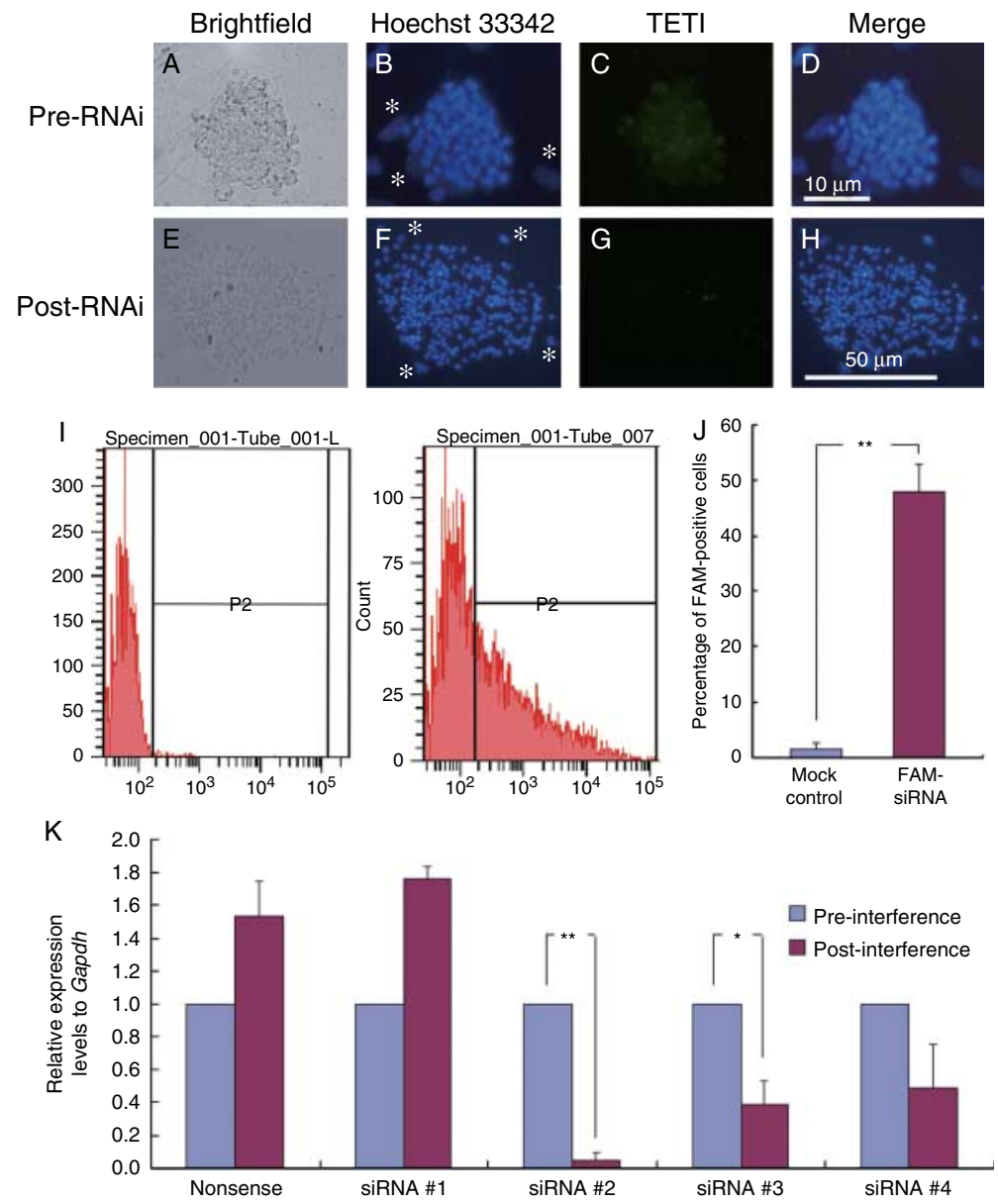

Figure 3 Targeting siRNA selection and downregulation of TET1. TET1 immunofluorescence staining in piPSC colonies cultured on feeder layers demonstrated its expression (A, B, C and D). Nuclear counterstaining was proceeded with Hoechst 33342. The downregulated expression of TET1 by siRNA \#2 transfection caused the piPSCs to differentiate (E, F, G and H). Negative staining of feeder layers, which have larger nuclei also provided another control (*). Detection of FAM-positive cells by FACS (I) indicated that the positive cells comprised $~ 50 \%$ of the population (J). Relative expression of TET1 detected by RT-PCR indicated that siRNA \#2 had the strongest downregulation effect (K). ${ }^{*} P<0.05$ and ${ }^{* *} P<0.01$ (Student's t-test). pigs (Esteban et al. 2009) were used as the sources to generate the iPSCs. In this study, Yorkshire pigs were chosen as a source for generating piPSCs. PEFs were used as a target for ectopical overexpression of SKOM to obtain the piPSCs. Whether reprogramming using cells from the different pig strains occurs with the same efficacy when using the same reprogramming system or not is still unknown. Different evolved and restricted environments may have imposed evolutionary changes and thus affect the suitability of different porcine cells for iPSCs generation. Our research of piPSCs from Yorkshire pigs may enrich the knowledge of piPSCs with a different background, but systematic analysis of the susceptibility of cells from the other pig strains to become iPSCs is important as well and remains to be observed. In addition, targeting cell types other than fibroblasts has been demonstrated to have a dramatic impact on iPSCs generation in other species, such as mouse meningeal membrane cells (Qin et al. 2008), neural progenitor cells (Eminli et al. 2008), and inneural stem cells (Kim et al. 2008) and human keratinocytes (Aasen et al. 2008), cord blood cells (Giorgetti et al. 2009), and adipose stem cells (Sun et al. 2009). In our previous study, different porcine cell types exhibited different capabilities of iPSCs generation (Tang et al. 2012). This discrepancy may be due to every particular cell type having a unique transcriptional program, epigenetic profile, and gene expression profile. Thus, efforts should be concentrated on finding a highly susceptible and accessible tissue or cell type that can be used to generate iPSCs for clinical applications.

Members of the Tet family of enzymes, including TET1, TET2, and TET3, convert $5 \mathrm{mC}$ to $5 \mathrm{hmC}$, and plus promote the demethylation of DNA (Tahiliani et al. 2009). TET1 is particularly abundant in mouse ESCs, and increased expression of TET1 was observed when mouse fibroblasts were reprogrammed into iPSCs (Koh et al. 2011). Two recent studies found that the RNAi-mediated knockdown of TET1 led to loss of the undifferentiated state in mouse ESCs (Ito et al. 2010, Freudenberg et al. 2012). By contrast, other groups reported that knockdown of TET1 caused no morphologically distinguishable changes in mouse ESCs (Dawlaty et al. 2011, Koh et al. 2011). Koh et al. (2011) pointed out that TET1 ${ }^{-/-}$ ESCs supported the development of live-born mice, although these mice had a slightly reduced body size. However, in a more recent report, significant reduction of oocyte numbers and fertility was observed in other TET1 knockout mice, and univalent chromosomes and unresolved DNA double-strand breaks were also 

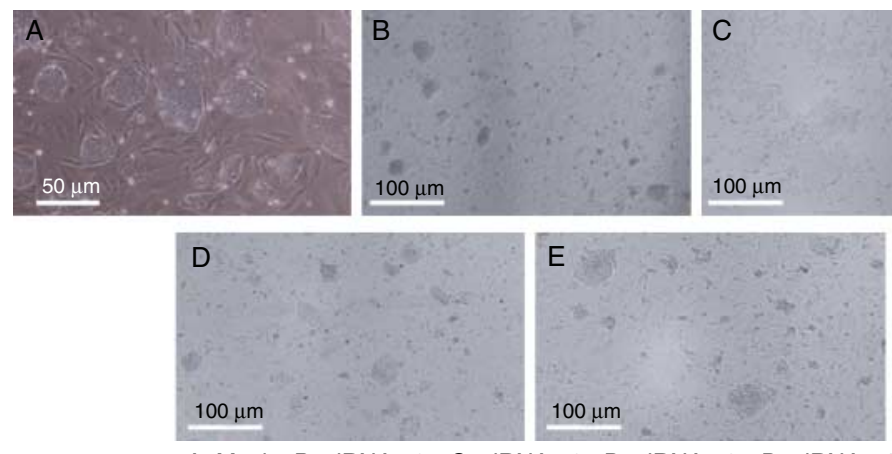

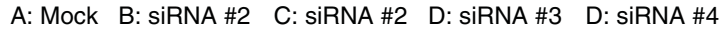

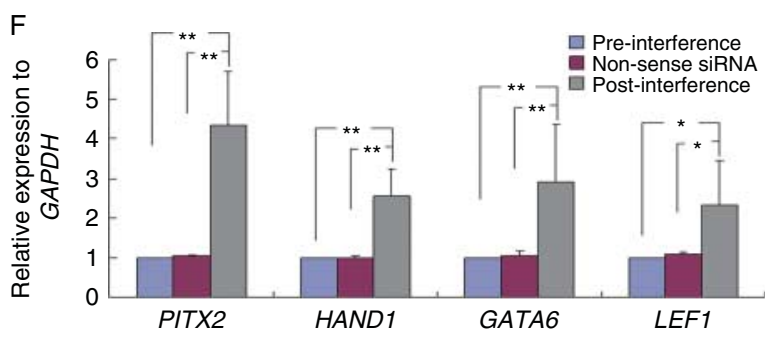

G

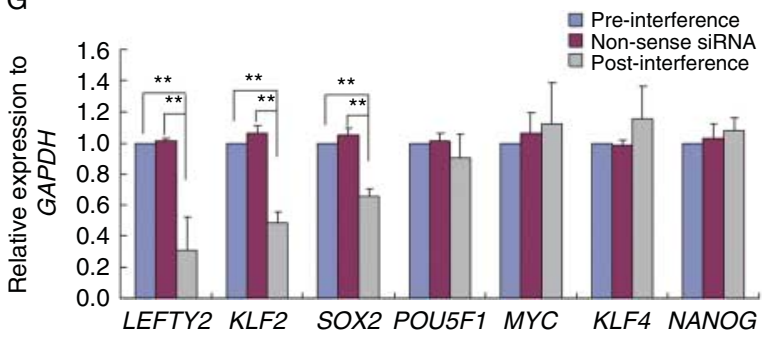

Figure 4 Morphological and gene expression changes in piPSCs after downregulation of TET1. Striking morphological changes were observed in the siRNA \#2 group $(C)$, whereas no similar results in other groups (A, B, D and E). It was also in this group that significant downregulation of TET1 was achieved (Fig. 3E). RT-PCR assays demonstrated that the expression of differentiation-related genes PITX2, HAND1, GATA6, and LEF1 was upregulated (F), whereas pluripotency-related genes $L E F T Y 2, K L F 2$, and SOX2 were downregulated, and POU5F1, MYC, $K L F 4$, and NANOG were not downregulated (G). ${ }^{*} P<0.05$ and ${ }^{* *} P<0.01$ (Student's t-test). observed (Yamaguchi et al. 2012). In the same study, it was found that TET1 deficiency led to defective DNA demethylation and decreased expression of a subset of meiotic genes but did not greatly affect the genome-wide demethylation in primordial germ cells. In addition, new papers have been published that describe the role of TET1 and TET2 in methylation reprogramming during fetal germline development and found that TET1, TET2, and $5 \mathrm{hmC}$ are dispensable for the initial global depletion of $5 \mathrm{mC}$ from the PGC genome; however, TET depletion had a locus-specific role in DNA demethylation in PGCs (Seisenberger et al. 2012, Hackett et al. 2013, Piccolo et al. 2013, Vincent et al. 2013). Here, we reported that TET1 was also expressed in piPSCs. After downregulation of TET1 using siRNA, colony morphological changes were observed. However, no similar outcome was found in the mock group or in other three TET1 siRNA groups in which the downregulation of TET1 was not as pronounced. Therefore, the possibility that the morphological changes were due to that siRNA off-target effects could be ruled out, and the morphological changes with differentiation were indeed induced by significant downregulation of TET1. The reasons for the discrepancies among these studies may be due to differences in the knockdown efficiencies, off-target effects, homeostatic compensation, or different mESC backgrounds. Therefore, efforts should be made in order to find what caused the controversy over whether TET1 was indispensable for the maintenance of the pluripotent state in $\mathrm{mESC}$.

In addition to causing morphological changes, the downregulation of TET1 also had an effect on the expression of many genes. Some studies reported that TET1 knockdown caused more genes to be upregulated than to be downregulated (Williams et al. 2011, Wu et al. 2011, Xu et al. 2011). The paradoxical phenomenon of TET1 causing both the upregulation of differentiation-related genes and the downregulation of pluripotency-related genes was demonstrated in several recent studies (Ito et al. 2010, Ficz et al. 2011, Koh et al. 2011, Williams et al. 2011, Wu et al. 2011, Freudenberg et al. 2012), which resembles the effects of some factors that function as both activators and repressors, such as esBAF, a specific chromatin remodeling factor (Ho et al. 2009a, 2009b). In this study, the differentiation-related genes PITX2 and LEF1 were upregulated, and HAND1 (trophectoderm marker) and GATA6 (primitive endoderm marker) were also upregulated, whereas the 


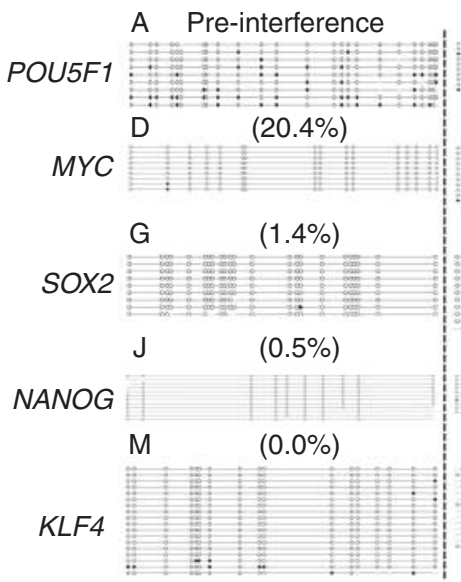

$(4.2 \%)$

$P$
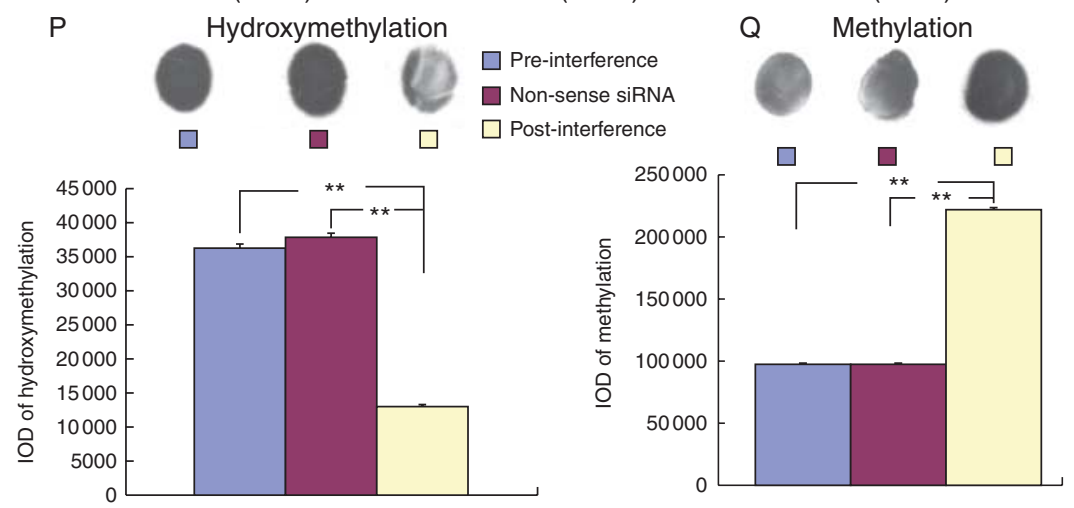

B Non-sense siRNA, C Post-interference \begin{tabular}{ll|l} 
E & $(23.3 \%)$ & $\mathrm{F}$ \\
$(85.4 \%)$
\end{tabular}

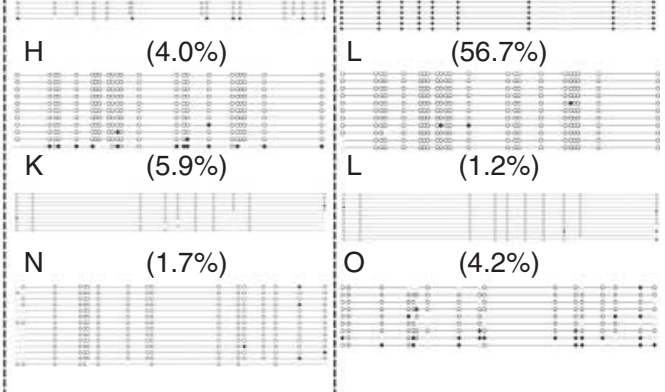

$(2.1 \%)$

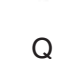

(7.4\%)

Q Methylation
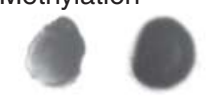
(D, E and F) ins of POU 5FI (A, B and C) and MYC and $F$ ) increased obviously, whereas it was barely changed for SOX2 (G, $\mathrm{H}$ and $\mathrm{I})$ and NANOG $(\mathrm{J}, \mathrm{K}$ and $\mathrm{L})$, and slightly increased for $\operatorname{KLF} 4(\mathrm{M}, \mathrm{N}$ and $\mathrm{O})$. The hydroxymethylation levels of the whole genomes decreased after TET1 siRNA interference $(\mathrm{P})$, whereas the methylation levels increased $(\mathrm{Q})$. The filled (black) circles correspond to methylated cytosines, the unfilled (white) circles correspond to unmethylated cytosines, and small vertical lines without a circle correspond to the missing values. ${ }^{* *} P<0.01$ (Student's t-test).

pluripotency-related genes LEFTY2, KLF2, and SOX2 were significantly downregulated. The pluripotencyrelated gene POU5F1 was slightly downregulated, but without significant difference. The fact that TET1 promoted the transcription of pluripotency factors may be the result of TET1-mediated promoters' hypomethylation excluding the binding of repression complexes that could recognize methylated sites and thus maintaining the expression of a group of transcriptionally active genes. The possibility exists that TET1 represses the expression of some genes by participating in the repression of Polycomb-targeted genes by the direct association of Sin3a and facilitating the recruitment of PRC2 at the transcription start site (TSS).

It was observed that TET1 was preferentially bound to the CpG-rich TSSs in gene promoters, especially those of transcriptionally active genes, and that DNA methylation was generally excluded from the TSSs of gene promoters with TET1 bound to them. By contrast, gene promoters that lacked TET1 were frequently methylated (Williams et al. 2011, Wu et al. 2011). Evaluation using the BSP method revealed that the methylation levels of the POU5F1 and MYC promoters were clearly increased, although their expression was not downregulated. The levels of methylation of the KLF4, SOX2, and NANOG promoters were not significantly changed, whereas
SOX2 gene expression was downregulated significantly and that of KLF4 barely changed. These results confirmed the aforementioned evidence that TET1 has dual functions but contradict the prevalent notion that hypermethylation is often inversely correlated with gene expression. The methylation levels increased in self-renewal genes POU5F1 and MYC but not changed in KLF4, SOX2, and NANOG following knockdown of TET1 could possibly be explained by the fact that TET1 had a locus-specific role in DNA demethylation just as it played in PGCs (Seisenberger et al. 2012, Hackett et al. 2013, Piccolo et al. 2013, Vincent et al. 2013). Recently, after fusion mouse B lines that carries a silent Oct-GFP with EGC lines, POU5F1-GFP was detected from day 3, although at this time the POU5F1 promoter still had a high methylation level (Piccolo et al. 2013). Similarly, in PGCs with a TET1 knockdown background, the increased methylation at BLIMP1 did not alter its expression (Vincent et al. 2013) and some downregulated genes, such as Stra8, showed no obvious change in DNA methylation (Yamaguchi et al. 2012). In addition, recent studies found that histone deacetylase inhibitors such as trichostatin A and depsipeptide produced gene reactivation from hypermethylated promoters without any changes in DNA methylation at the promoter level (Pruitt et al. 2006, Raynal et al. 2012). 
Seisenberger et al. (2012) found that the global loss of methylation at promoters did not result in a profound shift in transcriptional regulation. So the reason why methylation increases at self-renewal genes following knockdown of TET1, while their expression is maintained, may be that DNA methylation and transcription are largely uncoupled. Therefore, DNA methylation does not always lock gene expression. The relationship between DNA methylation and transcription is complex, so their expression may either be regulated indirectly by TET1 or be regulated in a DNA methylation-independent manner. In one recent study, it was found that after siRNA-mediated knockdown of TET1, the total 5hmC levels decreased (Freudenberg et al. 2012). The converse has been reported: overexpression of the TET1 catalytic domains greatly reduced the total $5 \mathrm{mC}$ (Ito et al. 2010). In this study, the total $5 \mathrm{mC}$ and $5 \mathrm{hmC}$ levels after the knockdown of TET1 were examined using the dot-blot method, and the results revealed that the level of $5 \mathrm{hmC}$ had decreased. The results may be caused by the enzymatic activity of TET1, which can oxidize $5 \mathrm{mC}$ to $5 \mathrm{hmC}$, and downregulation of Tet 1 impaired the process of conversion of $5 \mathrm{mC}$ to $5 \mathrm{hmC}$. Therefore, TET1 indeed plays important roles in conversion of $5 \mathrm{mC}$ to $5 \mathrm{hmC}$. The mild increase in $5 \mathrm{mC}$ in our study, combined with what others found in mouse PGC (Seisenberger et al. 2012, Hackett et al. 2013, Piccolo et al. 2013, Vincent et al. 2013), could be explained by TET1 depletion not regulating genome-wide DNA demethylation but having a local effect on promoter and gene body methylation, and this effect was a directional change of hypermethylation.

Taken collectively, TET1 is expressed in the piPSCs and can serve as a marker of pluripotency. Tet 1 may play important roles in maintaining the molecular identity of the piPSCs. These roles derive not only from its enzymatic activity in converting $5 \mathrm{mC}$ to $5 \mathrm{hmC}$, thus changing the methylation metabolism, but also from its dual function in regulating gene transcription. However, the full functional complexity of TET1 in pluripotent stem cells and development remains to be elucidated.

\section{Declaration of interest}

The authors declare that there is no conflict of interest that could be perceived as prejudicing the impartiality of the research reported.

\section{Funding}

This work was supported by the National Natural Science Foundation (no. 31271591), National Basic Research Program (no. 2009CB941001), and Program for Changjiang Scholars and Innovative Research Team in University (PCSIRT no. IRT1248) in China.

\section{Acknowledgements}

Ziyi Li, Xueming Zhang, and Anran Fan conceived and designed the experiments. Anran Fan, Yu Ding, Guangqi Song, Lina Tang, Kuiying Ma, and Xinglan An performed the experiments. Peng Zhang and Sheng Zhang analyzed the data. Anran Fan and Xueming Zhang wrote the paper. The authors thank Prof. Qi Zhou, Chinese Academy of Science (CAS), for kindly presenting retroviral vectors that are used in iPSCs induction.

\section{References}

Aasen T, Raya A, Barrero MJ, Garreta E, Consiglio A, Gonzalez F, Vassena R, Bilic J, Pekarik V, Tiscornia G et al. 2008 Efficient and rapid generation of induced pluripotent stem cells from human keratinocytes. Nature Biotechnology 26 1276-1284. (doi:10.1038/nbt.1503)

Bird A 2002 DNA methylation patterns and epigenetic memory. Genes and Development 16 6-21. (doi:10.1101/gad.947102)

Cedar H \& Bergman Y 2009 Linking DNA methylation and histone modification: patterns and paradigms. Nature Reviews. Genetics 10 295-304. (doi:10.1038/nrg2540)

Cheng L \& Xiao L 2009 Pig induced pluripotent stem cells: a new resource for generating genetically modified pigs. Regenerative Medicine $\mathbf{4}$ 787-789. (doi:10.2217/rme.09.56)

Dawlaty MM, Ganz K, Powell BE, Hu YC, Markoulaki S, Cheng AW, Gao Q, Kim J, Choi SW, Page DC et al. 2011 Tet1 is dispensable for maintaining pluripotency and its loss is compatible with embryonic and postnatal development. Cell Stem Cell 9 166-175. (doi:10.1016/j.stem. 2011.07.010)

Eminli S, Utikal J, Arnold K, Jaenisch R \& Hochedlinger K 2008 Reprogramming of neural progenitor cells into induced pluripotent stem cells in the absence of exogenous Sox2 expression. Stem Cells $\mathbf{2 6}$ 2467-2474. (doi:10.1634/stemcells.2008-0317)

Esteban MA, Xu J, Yang J, Peng M, Qin D, Li W, Jiang Z, Chen J, Deng K, Zhong M et al. 2009 Generation of induced pluripotent stem cell lines from Tibetan miniature pig. Journal of Biological Chemistry 284 17634-17640. (doi:10.1074/jbc.M109.008938)

Ezashi T, Telugu BP, Alexenko AP, Sachdev S, Sinha S \& Roberts RM 2009 Derivation of induced pluripotent stem cells from pig somatic cells. PNAS 106 10993-10998. (doi:10.1073/pnas.0905284106)

Ficz G, Branco MR, Seisenberger S, Santos F, Krueger F, Hore TA, Marques CJ, Andrews S \& Reik W 2011 Dynamic regulation of 5-hydroxymethylcytosine in mouse ES cells and during differentiation. Nature 473 398-402. (doi:10.1038/nature10008)

Freudenberg JM, Ghosh S, Lackford BL, Yellaboina S, Zheng X, Li R, Cuddapah S, Wade PA, Hu G \& Jothi R 2012 Acute depletion of Tet1dependent 5-hydroxymethylcytosine levels impairs LIF/Stat3 signaling and results in loss of embryonic stem cell identity. Nucleic Acids Research 40 3364-3377. (doi:10.1093/nar/gkr1253)

Giorgetti A, Montserrat N, Aasen T, Gonzalez F, Rodriguez-Piza I, Vassena R, Raya A, Boue S, Barrero MJ, Corbella BA et al. 2009 Generation of induced pluripotent stem cells from human cord blood using OCT4 and SOX2. Cell Stem Cell 5 353-357. (doi:10.1016/j.stem. 2009.09.008)

Hackett JA, Sengupta R, Zylicz JJ, Murakami K, Lee C, Down TA \& Surani MA 2013 Germline DNA demethylation dynamics and imprint erasure through 5-hydroxymethylcytosine. Science 339 448-452. (doi:10.1126/science.1229277)

Ho L, Jothi R, Ronan JL, Cui K, Zhao K \& Crabtree GR 2009a An embryonic stem cell chromatin remodeling complex, esBAF, is an essential component of the core pluripotency transcriptional network. PNAS 106 5187-5191. (doi:10.1073/pnas.0812888106)

Ho L, Ronan JL, Wu J, Staahl BT, Chen L, Kuo A, Lessard J, Nesvizhskii AI, Ranish J \& Crabtree GR 2009b An embryonic stem cell chromatin remodeling complex, esBAF, is essential for embryonic stem cell selfrenewal and pluripotency. PNAS 106 5181-5186. (doi:10.1073/pnas. 0812889106) 
Ito S, D'Alessio AC, Taranova OV, Hong K, Sowers LC \& Zhang Y 2010 Role of Tet proteins in $5 \mathrm{mC}$ to $5 \mathrm{hmC}$ conversion, ES-cell self-renewal and inner cell mass specification. Nature 466 1129-1133. (doi:10.1038/ nature09303)

Kim JB, Zaehres H, Wu G, Gentile L, Ko K, Sebastiano V, Arauzo-Bravo MJ, Ruau D, Han DW, Zenke M et al. 2008 Pluripotent stem cells induced from adult neural stem cells by reprogramming with two factors. Nature 454 646-650. (doi:10.1038/nature07061)

Koh KP, Yabuuchi A, Rao S, Huang Y, Cunniff K, Nardone J, Laiho A, Tahiliani M, Sommer CA, Mostoslavsky G et al. 2011 Tet1 and Tet2 regulate 5-hydroxymethylcytosine production and cell lineage specification in mouse embryonic stem cells. Cell Stem Cell 8 200-213. (doi:10.1016/j.stem.2011.01.008)

Livak KJ \& Schmittgen TD 2001 Analysis of relative gene expression data using real-time quantitative PCR and the $2(-$ Delta Delta $C(\mathrm{~T}))$ method. Methods 25 402-408. (doi:10.1006/meth.2001.1262)

Mattout A, Biran A \& Meshorer E 2011 Global epigenetic changes during somatic cell reprogramming to iPS cells. Journal of Molecular Cell Biology 3 341-350. (doi:10.1093/jmcb/mjr028)

Ooi SK \& Bestor TH 2008 The colorful history of active DNA demethylation. Cell 133 1145-1148. (doi:10.1016/j.cell.2008.06.009)

Park IH, Arora N, Huo H, Maherali N, Ahfeldt T, Shimamura A, Lensch MW, Cowan C, Hochedlinger K \& Daley GQ 2008 Diseasespecific induced pluripotent stem cells. Cell 134 877-886. (doi:10.1016/ j.cell.2008.07.041)

Piccolo FM, Bagci H, Brown KE, Landeira D, Soza-Ried J, Feytout A, Mooijman D, Hajkova P, Leitch HG, Tada T et al. 2013 Different roles for Tet1 and Tet2 proteins in reprogramming-mediated erasure of imprints induced by EGC fusion. Molecular Cell 49 1023-1033. (doi:10.1016/j. molcel.2013.01.032)

Pruitt K, Zinn RL, Ohm JE, McGarvey KM, Kang SH, Watkins DN, Herman JG \& Baylin SB 2006 Inhibition of SIRT1 reactivates silenced cancer genes without loss of promoter DNA hypermethylation. PLoS Genetics 2 e40. (doi:10.1371/journal.pgen.0020040)

Qin D, Gan Y, Shao K, Wang H, Li W, Wang T, He W, Xu J, Zhang Y, Kou Z et al. 2008 Mouse meningiocytes express Sox2 and yield high efficiency of chimeras after nuclear reprogramming with exogenous factors. Journal of Biological Chemistry 283 33730-33735. (doi:10.1074/jbc. M806788200)

Raynal NJ, Si J, Taby RF, Gharibyan V, Ahmed S, Jelinek J, Estecio MR \& Issa JP 2012 DNA methylation does not stably lock gene expression but instead serves as a molecular mark for gene silencing memory. Cancer Research 72 1170-1181. (doi:10.1158/0008-5472.CAN-11-3248)

Sasaki H \& Matsui Y 2008 Epigenetic events in mammalian germ-cell development: reprogramming and beyond. Nature Reviews. Genetics 9 129-140. (doi:10.1038/nrg2295)

Seisenberger S, Andrews S, Krueger F, Arand J, Walter J, Santos F, Popp C, Thienpont B, Dean W \& Reik W 2012 The dynamics of genome-wide DNA methylation reprogramming in mouse primordial germ cells. Molecular Cell 48 849-862. (doi:10.1016/j.molcel.2012.11.001)
Sun N, Panetta NJ, Gupta DM, Wilson KD, Lee A, Jia F, Hu S, Cherry AM, Robbins RC, Longaker MT et al. 2009 Feeder-free derivation of induced pluripotent stem cells from adult human adipose stem cells. PNAS 106 15720-15725. (doi:10.1073/pnas.0908450106)

Surani MA, Hayashi K \& Hajkova P 2007 Genetic and epigenetic regulators of pluripotency. Cell 128 747-762. (doi:10.1016/j.cell.2007. 02.010)

Tahiliani M, Koh KP, Shen Y, Pastor WA, Bandukwala H, Brudno Y, Agarwal S, lyer LM, Liu DR, Aravind L et al. 2009 Conversion of 5-methylcytosine to 5-hydroxymethylcytosine in mammalian DNA by MLL partner TET1. Science 324 930-935. (doi:10.1126/science. 1170116)

Takahashi K \& Yamanaka S 2006 Induction of pluripotent stem cells from mouse embryonic and adult fibroblast cultures by defined factors. Cell 126 663-676. (doi:10.1016/j.cell.2006.07.024)

Tang L, Yin Y, Zhou H, Song G, Fan A, Tang B, Shi W \& Li Z 2012 Proliferative capacity and pluripotent characteristics of porcine adult stem cells derived from adipose tissue and bone marrow. Cellular Reprogramming 14 342-352. (doi:10.1089/cell.2011.0098)

Vincent JJ, Huang Y, Chen PY, Feng S, Calvopina JH, Nee K, Lee SA, Le T, Yoon AJ, Faull K et al. 2013 Stage-specific roles for tet1 and tet2 in DNA demethylation in primordial germ cells. Cell Stem Cell 12 470-478. (doi:10.1016/j.stem.2013.01.016)

Williams K, Christensen J \& Pedersen MT 2011 TET1 and hydroxymethylcytosine in transcription and DNA methylation fidelity. Nature 473 343-348. (doi:10.1038/nature10066)

Wu Z, Chen J, Ren J, Bao L, Liao J, Cui C, Rao L, Li H, Gu Y, Dai H et al. 2009 Generation of pig induced pluripotent stem cells with a druginducible system. Journal of Molecular Cell Biology 1 46-54. (doi:10. 1093/jmcb/mjp003)

Wu H, D'Alessio AC, Ito S, Xia K, Wang Z, Cui K, Zhao K, Sun YE \& Zhang Y 2011 Dual functions of Tet1 in transcriptional regulation in mouse embryonic stem cells. Nature 473 389-393. (doi:10.1038/ nature09934)

Xu Y, Wu F, Tan L, Kong L, Xiong L, Deng J, Barbera AJ, Zheng L, Zhang H, Huang $\mathbf{S}$ et al. 2011 Genome-wide regulation of $5 \mathrm{hmC}, 5 \mathrm{mC}$, and gene expression by Tet1 hydroxylase in mouse embryonic stem cells. Molecular Cell 42 451-464. (doi:10.1016/j.molcel.2011.04.005)

Yamaguchi S, Hong K, Liu R, Shen L, Inoue A, Diep D, Zhang K \& Zhang Y 2012 Tet1 controls meiosis by regulating meiotic gene expression. Nature 492 443-447. (doi:10.1038/nature11709)

Received 16 May 2013

First decision 24 June 2013

Revised manuscript received 16 August 2013

Accepted 19 September 2013 